\title{
Facing Your Opponents: Social Identification and Information Feedback in Contests
}

\author{
Shakun D. Mago ${ }^{\mathrm{a}}$, Anya C. Savikhin ${ }^{\mathrm{b}}$ and Roman M. Sheremeta ${ }^{\mathrm{c}}$ \\ a Department of Economics, Robins School of Business, University of Richmond, \\ 1 Gateway Road, Richmond, VA 23173, USA \\ ${ }^{\mathrm{b}}$ Becker Friedman Institute for Economic Research, The University of Chicago, \\ 5807 South Woodlawn Avenue, Chicago, IL 60637, U.S.A. \\ ${ }^{c}$ Argyros School of Business and Economics, Chapman University, \\ One University Drive, Orange, CA 92866, U.S.A.
}

May 21, 2012

\begin{abstract}
We experimentally investigate the effect of social identification and information feedback on individual behavior in contests. Identifying subjects through photo display decreases efforts. Providing information feedback about others' effort does not affect the aggregate effort levels but it does change the dynamics of individual behavior. We develop a behavioral model based on relative payoff maximization, and use it to estimate the degree of pro-social/status-seeking behavior. We find that decrease in 'social distance' between group members through photo display promotes pro-social behavior. Information feedback reduces the within-group volatility in effort level and facilitates greater adherence to the 'group norm.' Finally, in contrast to standard theoretical predictions, we find significant over-expenditure of efforts in all treatments. This overdissipation can be explained by a combination of non-monetary utility of winning and relative payoff maximization.
\end{abstract}

JEL Classifications: C72, C91, D72, D74,

Keywords: contest, information, identification, over-dissipation, experiments

Corresponding author: Anya Savikhin, savikhin@uchicago.edu

* For helpful discussions and comments, we thank James Andreoni, Subhasish Chowdhury, Cary Deck, Joan Esteban, Uri Gneezy, Ernan Haruvy, Erik Kimbrough, Kai Konrad, Sherry Li, John Morgan, Brian Roberson, Sally Sadoff, Karim Sadrieh, Tim Salmon, Tim Shields, as well as seminar participants at the University of Taxes at Dallas, the University of California at San Diego, participants at the Western Economics Association International Conference, the Alliances and Alliance Formation in Conflict Workshop, and the Bay Area Behavioral and Experimental Economics Workshop. We thank University of Richmond for generous funding of this project and Kory Garner for help in conducting experiments. Any remaining errors are ours. 


\section{Introduction}

Individuals participating in contests and tournaments encounter disparate information feedback settings. Fellow contestants may be known or unknown, and their effort level may be observable or unobservable. In some contests, such as competition for a new job or admission to a university, fellow contestants are typically unknown and their effort level is unobservable. In other contests, such as promotions in the workplace and in political races, fellow contestants are often known and their effort level is observable. In patent races, opponents are usually known but their effort is unobservable. Such design details can have strong bearing on individual and group behavior, yet existing theory provides little guidance on their effect on decision-making.

Since the early attempts of Bull et al. (1987) and Millner and Pratt (1989), experimental literature on contests has been rapidly expanding, encompassing facets such as player asymmetry, entry costs, risk preferences, and contest structure. ${ }^{1}$ However, almost all of the existent laboratory studies focus on the actions of agents where identity of opponents is unknown and where there is ex post complete information feedback about each opponent's effort level. We argue that knowing the opponents' identities and effort levels are important design features that can influence individual behavior in contests. Existing literature does not provide a concrete answer as to the direction and the degree of how social identification and information feedback influence contestants' behavior. For instance, identification of participants may decrease 'social distance' between group members and foster more pro-social behavior, or it may instigate a quest to seek a higher social status relative to peers. Similarly, providing full information about others' efforts may foster implicit collusion and greater learning of 'group norm,' or it may

\footnotetext{
${ }^{1}$ For a review of the experimental literature on contests see Sheremeta et al. (2012) and for a review of the theoretical literature see Konrad (2009).
} 
generate regret and trigger more aggressive behavior. Each of these channels impacts the dynamics of individual behavior in contrasting and previously undocumented ways.

Different information feedback and varying degrees of social identification are also worthy of empirical investigation because contest designers often manipulate these features in practice (Smither et al., 2005). For instance, workplace managers may choose to explicitly identify the workers being considered for a promotion and make known their effort level, or they may choose to keep the identity of the workers being considered unknown (Harbring et al., 2007; Gürtler and Harbring, 2010). Politicians are required, by the Federal Election Campaign Act enacted in 1971 and revised in 1974, to disclose their campaign contributions and expenditures (Potter, 1999). ${ }^{2}$ In market settings, researchers show that greater transparency can generate trust and improve welfare (Rietz et al., 2012), but at the same time forced disclosure can hurt the disclosing party and can be used by buyers to obtain concessional prices (Thomas and Wilson, 2002; Cason and Plott, 2005). The impact of these diverse information settings on behavior in competitive contest environments is highly relevant but has not been studied to date partly because confounding factors in the field make traditional empirical analysis untenable.

We use a controlled laboratory experiment to investigate the effect of social identification and information feedback on individual and group behavior in a lottery contest, where individuals exert effort in order to win a prize. We consider a contest structure where higher efforts lead to more socially wasteful outcomes (i.e., rent-seeking and lobbying). Using this structure, we compare an information setting where all group members are completely

\footnotetext{
2 The U.S. Supreme Court has generally upheld laws requiring disclosure of campaign contributions and expenditures, but it has also ruled that disclosure can violate the First Amendment jurisprudence in certain contexts. In Buckley v. Valeo, the Supreme Court considered the constitutionality of requiring political committees to disclose the identity of contributors and the dollar amount of their contributions, as well as the size of their expenditures and the recipients of disbursements. Since First Amendment freedoms and campaign finance regulation present conflicting means of attempting to preserve the integrity of the political process, the Court resolved this conflict in favor of the First Amendment interests and subjected any regulation burdening free speech and free association to "exacting scrutiny" (Whitaker, 2008).
} 
anonymous to one where the identity of each group member is fully revealed to others using the member's photo and first name. We also compare information conditions in which members do not learn about other group members' efforts to one where they receive full information feedback about each group member's effort.

Our testable hypotheses, informed by previous literature, provide contrasting predictions. In the actual experiment, we find that identifying subjects through photo display decreases effort by $17 \%$. Providing information feedback about others' effort does not affect average effort but changes the dynamics of individual behavior. We develop a behavioral model based on relative payoff maximization and use it to estimate the degree of pro-social/status-seeking behavior. We find that decrease in 'social distance' between group members through photo display promotes pro-social behavior, and information feedback facilitates increased conformation to the 'group norm.' Subjects whose effort is higher than the winning effort in the previous period reduce their effort in the current period, and subjects whose effort is lower than the winning effort in the previous period increase their effort in the current period.

In contrast to standard theoretical predictions, but consistent with previous experimental literature, we observe significant over-expenditure of effort in all treatments. This overexpenditure can be explained by a combination of non-monetary utility of winning and relative payoff maximization. We find that $51 \%$ of subjects exhibit non-monetary utility of winning, which is neither influenced by social identification nor by information feedback. Furthermore, $67 \%$ of subjects behave as status-seekers by maximizing their relative payoffs. These findings contribute to the existing literature on rent-seeking, overbidding and contest design, and suggest directions for future research. 


\section{Experimental Environment and Testable Hypotheses}

\subsection{Experimental Design}

The experiment was conducted at the Vernon Smith Experimental Economics Laboratory at Purdue University. A total of 240 undergraduate student subjects participated in 12 sessions (3 sessions per treatment), with 20 subjects participating in each session. All subjects participated in only one session of this study. Some subjects had participated in other economics experiments that were unrelated to this research.

The computerized experimental sessions used z-Tree (Fischbacher, 2007) to record subject decisions and display photos of subjects. Upon arriving at the lab, each subject was photographed and then randomly assigned to a computer station. The experiment comprised of playing a lottery contest game for a total of 20 periods with a group of 4 participants. Each subject was randomly assigned to a group of 4 at the beginning of the experiment, and remained matched with the same group members for the duration of the experiment. At the beginning of each period, each subject received an endowment of 80 experimental francs and was asked to make an effort (choose a bid) in a lottery contest with a prize valued at 80 experimental francs. Each subject's probability of winning the prize was equal to his/her effort divided by the aggregate effort of all 4 participants in the group.

We conducted four treatments using a two-by-two design in which we varied the information feedback and the identification of group members (see Table 1). The only difference between the information treatments was the feedback provided to subjects at the end of each period (NI versus I). In the treatments with no information feedback (NP-NI and P-NI), we provided feedback only about the individual's own effort, earnings, and whether she won or not, but did not provide information about the efforts of other group members or the identity of the 
winner of the contest. In the treatments with information feedback (NP-I and P-I), we assigned each member an ID number (1-4), provided full information about each group member's effort and explicitly revealed (using the ID number) which subject's effort resulted in winning the contest at the end of each period. We varied the degree of social identification by varying whether or not the identities of participants were revealed to fellow group members (NP versus P). In treatments where no identities were revealed (NP-I and NP-NI), we did not provide any identifying information about other members in the group. On the other hand, in treatments P-NI and P-I, we provided photos and first names of each group member. ${ }^{3}$

At the end of the experiment, 2 out of 20 periods were selected for payment using a random draw from a bingo cage. Experimental francs were used throughout the experiment, with a conversion rate of 15 francs $=\$ 1$. The experimental earnings, including the $\$ 5$ participation fee, averaged $\$ 18.75$, and ranged from a low of $\$ 8.25$ to a high of $\$ 30.00 .{ }^{4}$ Sessions (including instruction time) lasted approximately 60-80 minutes. At the end of each session, subjects also completed a single-period game aimed at eliciting their non-monetary utility of winning, and a demographic questionnaire.

\subsection{Theoretical Model and Hypotheses}

The standard rent-seeking lottery contest assumes that $n$ identical risk-neutral individuals compete for a prize $v$ by exerting efforts. The probability that an individual $i$ wins the prize is equal to individual $i$ 's own effort $e_{i}$ divided by the sum of all individuals' efforts, i.e.,

\footnotetext{
${ }^{3}$ Before the beginning of the experiment, subjects in the P-NI and P-I treatments were asked to write their first names on a name card, and the experimenter took a photo of each subject holding up the name card. Similar to the design of Andreoni and Petrie (2004), we chose to use digital photos to identify subjects to one another because digital photos capture and preserve the appearance of the person but do not allow for communication, which may confound the effects of identification alone.

${ }^{4}$ Photographing participants in the photo identification treatments took more time, so an additional $\$ 5$ "surprise show up fee" was added at the end of the experiment in order to comply with the laboratory policies.
} 


$$
p_{i}\left(e_{i}, e_{-i}\right)=\frac{e_{i}}{\sum_{j=1}^{n} e_{j}}
$$

The individual's probability of winning increases monotonically in own effort and decreases in the opponents' efforts. The expected payoff for risk-neutral individual $i$ is given by

$$
E\left(e_{i}, e_{-i}\right)=p_{i}\left(e_{i}, e_{-i}\right) v-e_{i}
$$

That is, the probability of winning the prize $p_{i}\left(e_{i}, e_{-i}\right)$ times the prize value $v$ minus the cost of effort $e_{i}$. Differentiating (2) with respect to $e_{i}$ and accounting for the symmetric Nash equilibrium leads to a classical solution (Tullock, 1980):

$$
e=\frac{(n-1)}{n^{2}} v
$$

The degree of rent dissipation in the equilibrium can be calculated by summing up all efforts, i.e., ne, and dividing them by the prize value $v$ :

$$
d=\frac{(n-1)}{n}
$$

We extend the standard model of a lottery contest by considering several behavioral factors that are known to affect individual behavior. First, we assume that in addition to the value of the prize $v$, individuals also have a non-monetary value of winning $w$ (Sheremeta, 2010). Therefore, the updated expected payoff $E^{w}\left(e_{i}, e_{-i}\right)$ of individual $i$ is given by

$$
E^{w}\left(e_{i}, e_{-i}\right)=p_{i}\left(e_{i}, e_{-i}\right)(v+w)-e_{i}
$$

Second, we assume that individuals care about payoffs of others in their group. Following the convention established in evolutionary game theory (Leininger, 2003; Hehenkamp et al., 2004; Riechmann, 2007), we assume that in addition to own payoff, individual $i$ cares about the weighted average payoff of all group members, i.e., $E^{w}\left(e_{i}, e_{-i}\right)+\alpha \frac{1}{n} \sum_{j} E^{w}\left(e_{j}, e_{-j}\right)$, where $\alpha$ is 
the interdependent social payoff parameter. ${ }^{5} \alpha>0$ reflects preferences of pro-social individuals who strive to increase the payoff of the entire group, while $\alpha<0$ reflects preferences of statusseeking individuals who strive to obtain a higher relative payoff within the group.

Accounting for the behavioral factors captured by $w$ and $\alpha$, the expected payoff for a risk-neutral player $i$ is given by

$$
U_{i}\left(e_{i}, e_{-i}\right)=E^{w}\left(e_{i}, e_{-i}\right)+\alpha \frac{1}{n} \sum_{j} E^{w}\left(e_{j}, e_{-j}\right)
$$

Differentiating (6) with respect to $e_{i}$ and accounting for the symmetric Nash equilibrium gives us the equilibrium effort:

$$
e=\frac{(n-1)}{n(n+\alpha)}(v+w)
$$

The degree of rent dissipation in the equilibrium is given by

$$
d=\frac{(n-1)}{(n+\alpha)}\left(1+\frac{w}{v}\right)
$$

Both equilibrium effort (7) and rent dissipation (8) increase in the non-monetary utility of winning $w$, i.e., $\frac{\partial e}{\partial w}>0$, and decrease in the social payoff parameter $\alpha$, i.e., $\frac{\partial e}{\partial \alpha}<0$.

The interdependent social payoff parameter $\alpha$ represents a measure of how individuals weight their payoffs relative to others. We study two mechanisms that may impact $\alpha$, and consequently the individual behavior in contests: social identification and information feedback. As mentioned in the introduction, there is no consensus in the literature. Accordingly, our testable hypotheses reflect the contrasting viewpoints, as informed by the previous work in social psychology and economics.

\footnotetext{
${ }^{5}$ Evolutionary game theory often assumes that players care about the absolute difference in payoffs, i.e., their "survival" payoff. Here, we assume that players care about absolute and weighted payoffs. This is a more common assumption in the social preference literature (Fehr and Schmidt, 1999).
} 
Social Identification: A decrease in 'social distance' increases the value of the social payoff parameter $\alpha$, and according to our behavioral model should decrease efforts in the contest. ${ }^{6}$ Revealing individual identities is one way to reduce social distance between the individual and other members in the group and induce pro-social behavior (Andreoni and Petrie, 2004; Rege and Telle, 2004; Savikhin and Sheremeta, 2011). ${ }^{7}$ Bohnet and Frey (1999a, 1999b) and Burnham (2003) find that visual identification increases cooperation in prisoner's dilemma and dictator games. Eckel and Wilson (2006) find that seeing one's partner impacts trust and trustworthiness. Andreoni and Petrie (2004) and Savikhin and Sheremeta (2011) find that revealing identities enhances pro-social behavior and increases contributions to the public goods game. If identification of participants does indeed reduce the social distance between group members and causes players become more pro-social (higher $\alpha$ ), we would expect for identification to decrease efforts in the contest.

On the other hand, individuals may care about social status, and will engage in costly activities in order to achieve higher status relative to their peers (Frank, 1985). Moldovanu et al. (2007) and Dubey and Geanakoplos (2010) formally introduced status into contests. Ball et al. (2001) provide experimental evidence that social status plays a role in market exchanges. In our experiment, revealing identities of group members may trigger more status-seeking behavior (lower $\alpha$ ), and thus cause participants to exert higher efforts. Therefore, identifying individuals through photo display may either (1) enhance pro-social behavior, decreasing the average effort in contests, or (2) trigger more status-seeking behavior, increasing the average effort. It is

\footnotetext{
${ }^{6}$ Hoffman et al. (1996, pg. 654) define social distance to be the "degree of reciprocity that subjects believe exist within a social interaction."

${ }^{7}$ Eckel and Petrie (2011) attribute this in part to the association of attractiveness and skin tone with expectations about a partner's behavior. Another potential explanation of why photo display enhances pro-social behavior is based on group social identity theory (Tajfel and Turner, 1979; Ahmed, 2007; Chen and Li, 2009). In addition to revealing identities, in related work Scharleman et al. (2001) find that "smiles" can elicit cooperation among strangers in a one-shot bargaining interaction.
} 
possible that these two effects may arise simultaneously and negate each other, effectively resulting in unchanged average effort. We propose three alternative hypotheses regarding identification of subjects:

Hypothesis 1a: Identifying individuals decreases the average effort.

Hypothesis 1b: Identifying individuals increases the average effort.

Hypothesis 1c: Identifying individuals does not change the average effort.

Information Feedback: Akerlof and Kranton (2000) propose that people in a group internalize that group's behavioral norms, causing disutility to deviations from those norms. We conjecture that information feedback facilitates the creation of these group norms. Information about others' efforts can affect individual behavior in contests through several channels. We propose hypotheses based on (1) regret, (2) collusion and (3) learning, which predict different directional shifts in individual effort. First, information feedback that includes all efforts may give rise to regret and/or disappointment. The basic concept of regret, analyzed by EngelbrechtWiggans and Katok $(2007,2008)$ in the first price auction literature, is that the winner of the auction may regret paying too much relative to the second highest bid (winner regret) and the loser may regret missing a profitable trade opportunity by bidding too low (loser regret). Regret theory predicts that bids (efforts) should decrease in winner regret and increase in loser regret. Since regret effects work in the opposite direction and the equilibrium bid level depends on the relative weight of each type of regret, the precise effect of full information disclosure cannot be predicted a priori (Engelbrecht-Wiggans and Katok, 2009). However, recent experimental research finds strong evidence for loser and not winner regret (Filiz-Ozbay and Ozbay, 2007). In our setting, the contest winner is determined probabilistically (i.e., the individual exerting the highest effort is most likely, but not certain, to win) which diminishes the extent of winner 
regret. Since both the structure of our lottery contest and previous experimental findings suggest that loser regret is likely to dominate winner regret, it follows that in case of full information feedback lower interdependent payoff parameter $\alpha$ leads participants to exert higher efforts.

In sharp contrast, full information can foster implicit collusion among contestants (analogous to higher $\alpha$ ), resulting in lower effort. Isaac and Walker (1985) find that in auctions with four bidders, bidding levels decrease when bidders receive information feedback about all bids. Similarly, Dufwenberg and Gneezy (2002) find that reporting the entire distribution of prices facilitates collusion in a first-price auction.

Finally, full information feedback can facilitate faster learning of the incentives inherent in the contest structure, and decrease over-expenditure by promoting greater adherence to group norms. Inexperience and bounded rationality are often cited as factors contributing to irrational over-expenditures in contests (Davis and Reilly, 1998; Sheremeta, 2011). When information about all individual efforts is public knowledge, subjects may learn about profitable strategies more quickly from the experience of others, and thus additional information about others' actions should reduce irrational over-expenditures in the contest.

In sum, there are several alternative predictions for how full information feedback may impact individual effort in contests. Based on theoretical and experimental findings related to regret, we expect information feedback to increase the average effort. On the other hand, full information may encourage collusion and/or enhance learning, which would result in lower average effort. It is possible that all of these effects act simultaneously, effectively resulting in unchanged average effort. Although our treatments allow us to determine whether and in what direction information about others' efforts affects individual effort, our experiment is not 
designed to disentangle the various effects. We propose three alternative hypotheses regarding information feedback.

Hypothesis 2a: Providing information about others' efforts increases the average effort.

Hypothesis 2b: Providing information about others' efforts decreases the average effort.

Hypothesis 2c: Providing information about others' efforts does not change the average effort.

\section{Results and Discussion}

\subsection{Overview}

Table 2 summarizes average efforts, payoffs, and dissipation rates for all 4 treatments. According to standard theoretical predictions derived in Section 2.2, in equilibrium all subjects should exert an effort of 15 and the resulting dissipation rate should be $0.75{ }^{8}$ On average, the observed dissipation rate in all treatments is significantly greater than predicted (Wilcoxon signed-rank test, all p-values $<0.05, \mathrm{n}=15) .{ }^{9}$ Figure 1 displays the average effort by treatment across all 20 periods. As subjects become more experienced, the average effort in all treatments decreases, but remains significantly higher than the Nash equilibrium prediction. As demonstrated in Figure 2, there is also substantial heterogeneity in individual efforts. Efforts range from 0 to 80 , which is inconsistent with play at a unique pure strategy Nash equilibrium of 15. Overall, these findings closely replicate the findings of other experimental studies on lottery contests (Millner and Pratt, 1989; Davis and Reilly, 1998; Sheremeta and Zhang, 2010;

\footnotetext{
${ }^{8}$ According to equation (3), individual effort $e=80(4-1) / 16=15$. According to equation (4), degree of rent dissipation $d=(4-1) / 4=0.75$.

${ }^{9}$ The non-parametric tests employ each group of four subjects as an independent observation.
} 
Sheremeta, 2010, 2011; Mago et al., 2011; Price and Sheremeta, 2011; Chowdhury et al., 2012). In the following sections, we examine the identification and information treatment effects.

\subsection{Social Identification}

According to Hypotheses 1a-1c, identifying individuals through photo display may increase, decrease or not change individual effort relative to treatments with no identification. Our data are consistent with Hypothesis 1a, as the average effort of 25.1 in P-NI is lower than the average effort of 29.1 in NP-NI, and the average effort of 24.1 in P-I is lower than the average effort of 28.3 in NP-I. Although pair-wise treatment comparisons are not significant at the conventional level (Mann-Whitney test, $\mathrm{p}$-values=0.14 and 0.24; $\mathrm{n}=\mathrm{m}=15$ ), combining data from both photo treatments and comparing it to data from no-photo treatments, we find that photo display (or social identification) significantly reduces the average effort (28.7 versus 24.6: MannWhitney test, $\mathrm{p}$-value $=0.06 ; \mathrm{n}=\mathrm{m}=30$ ). On average, effort decreases by $17 \%$ when group members are identified through photo display, suggesting that identification of participants decreases 'social distance' and encourages more pro-social behavior. Random effect panel regression with clustering at the group level also supports this result (cf. Table 5, p-value $=0.05$ ).

Result 1: Identifying group members through photo display decreases average effort (support for Hypothesis 1a).

We also consider how the role of identification differs in early rounds compared to later rounds. Because group composition remains unchanged throughout the experiment, there is room for reputation building and 'signaling.' Individuals in treatments with identification may choose to exert lower efforts in early periods to 'signal' cooperative behavior to other group members in expectation of sustaining such cooperation throughout the experiment. Figure 1 displays, by 
treatment, the average effort in periods 1-5, 6-10, 11-15 and 16-20. We find that efforts averaged across the first 5 periods are significantly lower with identification as compared to without identification (27.3 versus 31.4, Mann-Whitney test, $\mathrm{p}$-value=0.05; $\mathrm{n}=\mathrm{m}=30$ ). However, in later periods 16-20, efforts are not significantly different between treatments with identification and treatments without identification (23.4 versus 25.3, Mann-Whitney test, $\mathrm{p}$-value=0.66; $\mathrm{n}=\mathrm{m}=30$ ). Therefore, the major impact of identification on individual behavior in contests comes from the early periods of the experiment. This is consistent with the research of Lugovskyy et al. (2010), who observe tacit collusion in an all-pay auction, but find that collusive behavior dissipates after the first 10 periods. Further, while aggregate efforts decline in all four treatments, the rate of decline in the photo identification treatments is lower compared to treatments without identification.

\subsection{Information Feedback}

According to Hypotheses 2a-2c, revealing information about others' efforts may increase, decrease or not change individual effort relative to treatments with no information. Our data are consistent with Hypothesis 2c, as the average effort of 29.1 in NP-NI is not significantly different from the average effort of 28.3 in NP-I and that the average effort of 25.1 in P-NI is not significantly different from the average effort of 24.1 (Mann-Whitney test, p-values=0.98 and 0.55; $\mathrm{n}=\mathrm{m}=15)$. Combining the data from both information treatments and comparing it to the data from the no-information treatments, we still find no significant impact of information on effort (26.7 versus 27.1: Mann-Whitney test, $\mathrm{p}$-value $=0.63 ; \mathrm{n}=\mathrm{m}=30$ ). Panel data regression in Table 5 also supports this finding (p-value=0.85). 
Result 2: Providing information about others' efforts does not have a significant effect on the average effort level (support for Hypothesis 2c).

Does information about others' efforts affect the volatility of efforts? Table 3 provides two different measurements of volatility of efforts. The within group volatility in period $t$ is calculated as the absolute difference between individual effort and average group effort in period t. The between period volatility in period $t$ is calculated as the absolute difference between individual effort made in period $t$ and in period $t$-1. Table 3 displays, by treatment, these volatility measures for periods $1-5$, periods $16-20$ and all 20 periods of the experiment. The average value of the within group effort volatility in the information treatments (NP-I and P-I) is significantly lower than in the no information treatments (NP-NI and P-NI), when comparing all periods (16.0 versus 13.4; Mann-Whitney test, $\mathrm{p}$-value $=0.03 ; \mathrm{n}=\mathrm{m}=30$ ) and the first five periods (15.3 versus 12.8; Mann-Whitney test, $\mathrm{p}$-value $=0.05 ; \mathrm{n}=\mathrm{m}=30$ ). However, there is no significant difference in the average value of the between period effort volatility (all p-values $>0.5$ ). Therefore, it appears that information feedback does not impact aggregate volatility of individual effort across periods, but it does make effort levels more uniform within a given group. The fact that effort levels become more uniform with full information feedback suggests that this information causes subjects to learn to conform to the 'group norm.'

Next we examine the mechanism through which information influences the dynamics of individual behavior. Table 4 displays a panel regression that measures the impact of different lag variables in period $t-1$ on effort in period $t$. When subjects receive no feedback information about others' efforts (specification 1), we find that the major predictor of individual effort is the effortlag variable, i.e., their own effort in period $t-1 .{ }^{10}$ The effort-lag variable remains a significant

\footnotetext{
${ }^{10}$ Note that in treatments NP-NI and P-NI, subjects actually do not learn whether their effort in $t-1$ was above or below the winning effort. However, the above-lag and below-lag variables in specification (1) are included to
} 
predictor of effort even when subjects receive full feedback about others' efforts (specification 2). In addition, above-lag and below-lag variables are significant in specification (2). The negative and significant above-lag variable indicates that subjects whose effort is higher than the winning effort in period $t-1$ reduce their effort in period $t$; and the positive and significant belowlag variable indicates that subjects whose effort is lower than the winning effort in period $t-1$ increase their effort in period $t$.

Result 3: Providing information about others' efforts significantly affects the dynamics of individual effort.

These dynamics of individual effort can explain several patterns in our data. First, it can explain why we find no significant impact of information on the average effort - there are two opposing effects acting simultaneously (i.e., above-lag and below-lag) that on average counterbalance each other. Second, the negative above-lag and positive below-lag variables imply that over time efforts within the group should become more uniform, explaining why information significantly reduces within-group volatility. Finally, the significant lag variables imply substantial between period volatility of efforts which persists over all periods of the experiment. In sum, the results of our experiment indicate that providing information feedback promotes the 'group norm.' Adherence to this norm does not affect the aggregate level of dissipation in contests but it does change the dynamics of individual behavior by reducing within-group volatility.

facilitate the comparison with specification (2). The estimation results of specification (1) are virtually the same when we exclude these two variables from the estimation of specification (1). 


\subsection{Non-Monetary Utility of Winning}

The non-monetary utility of winning $w$ is not directly observable, but can be elicited through a simple task (Sheremeta, 2010; Price and Sheremeta, 2011). In a 'surprise' additional period at the end of the experiment, all subjects were given an endowment of 80 francs, and participated in a lottery contest for a prize valued at $v=0$ francs. Subjects were explicitly told that their effort is costly and that the cost of effort would be subtracted from their earnings. We find that $51 \%$ of subjects indicate a non-monetary utility of winning by exerting positive efforts for the prize valued at 0 francs, with about $25 \%$ of subjects choosing efforts higher than 10 francs (equivalent to $\$ 0.67$ ).

To analyze the extent to which non-monetary utility of winning affects subjects' efforts, we provide panel regression analysis in Table 5, where the dependent variable is the subject's effort and the independent variables are a period trend, treatment dummy-variables, and their non-monetary effort. The standard errors are clustered at the group level. Specification (1) indicates a significant and positive correlation between effort and the non-monetary variable. This finding suggests that winning is a component in a subject's utility, and that non-monetary utility of winning may partially explain over-expenditures in contests. ${ }^{11}$

We may expect that the non-monetary utility of winning is also affected by an increase in utility from being identified as a winner in the photo treatments P-NI and P-I. We find that the non-monetary utility of winning is not significantly different across treatments. Efforts for the prize of zero are slightly higher in the no-photo treatments NP-NI and NP-I than in the photo treatments P-NI and P-I (the average of 9.2 versus 7.0), but the difference is not significant

\footnotetext{
${ }^{11}$ One may argue that the non-monetary utility of winning coefficient is capturing confusion instead of a nonmonetary utility of winning. We control for confusion by using the quiz variable that measures the number of correct answers on the quiz, which was administered right after the instructions. Consistent with the intuition, we find that subjects who understand the instructions exert lower efforts, but this result is only marginally significant for the P-I treatment. Despite controlling for confusion, the non-monetary coefficient is positive and significant.
} 
(Mann-Whitney test, $\mathrm{p}$-value $=0.27 ; \mathrm{n}=\mathrm{m}=120$ ). Moreover, all pair-wise treatment comparisons show no significant difference across treatments (Mann-Whitney test, all p-values>0.15; $n=m=60)$.

Result 4: Subjects exhibit non-monetary utility of winning, and the level is neither impacted by information about others' efforts nor by identification of group members.

This result suggests that the differences in behavior observed in our treatments are due to changes in the interdependent social payoff parameter $\alpha$, and not due to changes in the nonmonetary utility of winning $w$. In the next section, we explore the treatment differences from the point of view of evolutionary game theory and relative payoff maximization.

\subsection{Relative Payoff Maximization}

Evolutionary game theory postulates that players aim to "beat" each other. For finite populations, Leininger (2003) and Hehenkamp et al. (2004) show that evolutionary stable behavior in lottery contests leads to higher efforts than predicted by Nash equilibrium. This overdissipation arises mainly because the tenet of "absolute payoff maximization" is replaced by "relative payoff maximization" - an aggressive player may not do well in absolute terms, but may do well in relative terms. ${ }^{12}$ A higher effort will lower the player's absolute payoff, but at the same time it will reduce the opponent's payoff even more, such that the player's loss in absolute terms is outweighed by her gain in relative terms.

Our behavioral model incorporates relative payoff maximization through the interdependent social payoff parameter $\alpha$, which also reflects the degree of social distance. We can calculate the actual value of $\alpha$ in the experiment. To do this, we first derive from equation

\footnotetext{
${ }^{12}$ Vriend (2000) and Reichmann (2006) also show that learning by imitation of successful others is also equivalent to maximizing relative payoffs.
} 
(7) the effort $e_{0}$ that symmetric contestants, having a non-monetary utility of winning $w$, should exert in a contest with the prize of zero (i.e., $v=0$ ):

$$
e_{0}=\frac{(n-1)}{n(n+\alpha)} w
$$

Next from equations (7) and (9) we can derive the value of $\alpha$ :

$$
\alpha=\frac{(n-1)}{n\left(e-e_{0}\right)} v-n
$$

Using the observed average effort $e$ for the prize of 80 francs and the effort $e_{0}$ for the prize of 0 francs, we estimate the value of $\alpha$ for each subject. Upon calculating individualspecific $\alpha$ for each subject we find that $67 \%$ of subjects behave as status-seekers, i.e., $\alpha<0$. These subjects behave as if they are relative payoff maximizers, i.e., they maximize the difference between their own payoff and weighted payoffs of other group members; and their evolutionary stable strategies provide an equilibrium explanation for the observed overexpenditure (Leininger, 2003; Hehenkamp et al., 2004). This quest to seek higher expected payoff than others is also consistent with the 'spite effect' contended by Hamilton (1970) or 'survival of the fittest' contended by Alchian (1950).

Result 5: Majority of subjects behave as status seekers by maximizing relative payoffs.

In Section 2.2, we conjectured that photo display may either reduce social distance and enhance more pro-social behavior (higher $\alpha$ ) or trigger more status-seeking behavior (lower $\alpha$ ). We find that the average value of the social payoff parameter $\alpha$ is higher in the photo treatments than in the no-photo treatments $(-0.59$ versus -0.90$) .{ }^{13}$ As a consequence, decreased social distance reduces the over-expenditure of efforts: the average effort of 24.6 in the photo

\footnotetext{
${ }^{13}$ The median value of the social payoff parameter $\alpha$ is also lower in the photo treatments than in the no-photo treatments $(-1.15$ versus -1.48$)$.
} 
treatments (P-NI and P-I) is lower than the average effort of 28.7 in the no-photo treatments (NPNI and NP-I).

\section{Conclusion}

What happens to competitive behavior in contests when identities of other participants and information about their effort are revealed has thus far remained an open question. Does such information increase or decrease individual effort? Examples of practical applications include college admissions, workplace promotions, patent races, political lobbying and competition for monopolistic rents. To the best of our knowledge, our study is the first to examine behavior in this information vacuum.

Using a behavioral model based on relative payoff maximization we explain how photo display and information feedback can affect individual behavior. We provide evidence that identifying participants through photo display reduces over-expenditure of efforts in contests by decreasing the social distance between group members. Providing information feedback about others' effort does not affect average effort but it does change the dynamics of individual behavior. We propose that information feedback facilitates greater adherence to the 'group norm.' Subjects whose effort is higher than the winning effort in the previous period reduce their effort in the current period, and subjects whose effort is lower than the winning effort in the previous period increase their effort in the current period.

Our results contribute to several areas of research. First, our study contributes to the discussion of why there is over-expenditure of efforts in contests. Over the past decade, a number of studies have offered various explanations such as mistakes (Potters et al., 1998; Sheremeta, 2011), judgmental biases and non-monotonic probability weighting (Amaldoss and 
Rapoport, 2009; Kalra and Shi, 2010). Our findings suggest that over-expenditure in contests can also be explained by a combination of a non-monetary utility of winning and relative payoff maximization. Moreover, we find that such over-expenditure can be reduced by identifying participants through photo display.

Our study also contributes to the literature investigating how feedback about relative performance impacts individual behavior in contests, which has been an area of interest in many workplace settings (Smither et al., 2005). Kuhnen and Tymula (2012), for example, find that after receiving feedback, subjects who rank higher in a contest decrease their effort, while subjects who rank lower increase their effort. Similarly, Ludwig and Lünser (2009), document that in a two-stage contest, contestants who lag behind tend to raise their effort in the second stage, while those who lead tend to reduce their effort. Interestingly enough, Ludwig and Lünser (2009) also find that on average there is no significant difference in total effort between the feedback and the no-feedback treatments. Together with these experiments, the results of our experiment indicate that providing information feedback creates a 'group norm.' Adherence to this norm does not affect the aggregate level of dissipation in contests but does change the dynamics of individual behavior.

There are many avenues for future research. Given the strong impact of social recognition on individual behavior, it would be interesting to investigate other settings by varying the degree of social consciousness of players. One potential direction for future research is to investigate behavior when endowments are asymmetric. When endowments are asymmetric, the effect of displaying photos may be stronger as players with greater endowment may feel more conscious about exerting higher effort and thus imposing higher negative externality on their team 
members. Future work should also aim to disentangle the effects of regret, collusion and learning that can drive changes in behavior as a result of greater information feedback. ${ }^{14}$

Finally, it is important to examine how individuals would self-select into alternative contests, knowing that their identities may be revealed. On the one hand, the results of our experiment indicate that in treatments with revealed identities subjects exert significantly lower efforts and thus earn higher payoffs. On the other hand, subjects may be averse to having their identities revealed and thus may avoid more profitable but less "private" contests. We leave these questions for future research.

\footnotetext{
${ }^{14}$ For example, to disentangle winner and loser regret in contests, one could build on the design of Filiz-Ozbay and Ozbay (2007), where only the winner's effort or only the loser's efforts are revealed at the end of each interaction.
} 


\section{References}

Ahmed, A.M. (2007). Group identity, social distance and intergroup bias. Journal of Economic Psychology, 28, 324-337.

Akerlof, G. \& Kranton, R. (2000). Economics and Identity. Quarterly Journal of Economics, $115,715-753$.

Alchian, A. (1950). Uncertainty, evolution and economic theory. Journal of Political Economy, 58, 211-221.

Amaldoss, W., \& Rapoport, A. (2009). Excessive expenditure in two-stage contests: Theory and experimental evidence. In F. Columbus (Ed.), Game Theory: Strategies, Equilibria, and Theorems. Hauppauge, NY: Nova Science Publishers.

Andreoni, J., \& Petrie, R. (2004). Public goods experiments without confidentiality: a glimpse into fund-raising. Journal of Public Economics, 88, 1605-1623.

Ball, S., Eckel, C., Grossman, P.J., \& Zame, W. (2001). Status in Markets. Quarterly Journal of Economics, 116, 161-188.

Bohnet, I., \& Frey, B.S. (1999a). Social Distance and Other-Regarding Behavior in Dictator Games: Comment. American Economic Review, 89, 335-339.

Bohnet, I., \& Frey, B.S. (1999b). The sound of silence in prisoner's dilemma and dictator games. Journal of Economic Behavior and Organization, 38, 43-57.

Bull, C., Schotter, A., \& Weigelt, K., (1987). Tournaments and piece rates: an experimental study. Journal of Political Economy, 95, 1-33.

Burnham, T.C. (2003). Engineering altruism: a theoretical and experimental investigation of anonymity and gift giving. Journal of Economic Behavior and Organization, 50, 133-144.

Cason, T.N., \& Plott, C.R., (2005). Forced Information Disclosure and the Fallacy of Transparency in Markets. Economic Inquiry, 43, 699-714.

Chen, Y., \& Li, S.X. (2009). Group Identity and Social Preferences. American Economic Review, 99, 431-57.

Chowdhury, S.M., Sheremeta, R.M., Turocy, T.L. (2012). Overdissipation and Convergence in Rent-Seeking Experiments: Cost Structure and Prize Allocation Rules. ESI Working Paper.

Davis, D., \& Reilly, R. (1998). Do Many Cooks Always Spoil the Stew? An Experimental Analysis of Rent Seeking and the Role of a Strategic Buyer. Public Choice, 95, 89-115.

Dubey, P., \& Geanakoplos, J. (2010). Grading Exams: 100, 99,...,1 or A, B, C? Incentives in Games of Status. Games and Economic Behavior, 69, 72-94.

Dufwenberg, M., \& Gneezy, U. (2002). Information Disclosure in Auctions: An Experiment. Journal of Economic Behavior and Organization, 48, 431-444.

Eckel, C., \& Petrie, R. (2011). Face Value. American Economic Review, 101, 1497-1513.

Eckel, C., \& Wilson, R. (2006). Internet cautions: Experimental games with internet partners. Experimental Economics, 9, 53-66.

Engelbrecht-Wiggans, R., \& Katok, E. (2007). Regret in Auctions: Theory and Evidence. Economic Theory, 33, 81-101.

Engelbrecht-Wiggans, R., \& Katok, E. (2008). Regret and Feedback Information in First-Price Sealed-Bid Auctions. Management Science, 54, 808-819.

Engelbrecht-Wiggans, R., and Katok, E. (2009). A Direct Test of Risk Aversion and Regret in First Price Sealed-Bid Auctions. Decision Analysis, 6, 75-86.

Fehr, E., \& Schmidt, K. (1999). A Theory of Fairness, Competition, and Cooperation. Quarterly Journal of Economics, 114, 817-868. 
Filiz-Ozbay, E., \& Ozbay, E. Y. (2007). Auctions with Anticipated Regret: Theory and Experiment. American Economic Review, 97, 1407-1418.

Fischbacher, U. (2007). z-Tree: Zurich Toolbox for Ready-Made Economic Experiments. Experimental Economics, 10, 171-178.

Frank, R.H. (1985). Choosing the Right Pond: Human Behavior and the Quest for Status. Oxford University Press.

Gürtler, O. \& Harbring, C. (2010). Feedback in Tournaments under Commitment Problems: Experimental Evidence. Journal of Economics and Management Strategy, 19, 771-810.

Hamilton, W. D. (1970). Selfish and spiteful behavior in evolutionary model. Nature, 228, 12181220.

Harbring, C., Irlenbusch, B. Krakel, M., \& Selten, R. (2007). Sabotage in Corporate Contests An Experimental Analysis. International Journal of the Economics of Business, 14, 367-392.

Hehenkamp, B., Leininger, W., \& Possajenikov, A. (2004). Evolutionary equilibrium in Tullock contests: spite and overdissipation. European Journal of Political Economy, 20, 1045-1057.

Hoffman, E., McCabe, K., \& Smith, V. (1996). Social Distance and Other-Regarding Behavior in Dictator Games. American Economic Review, 86, 653-660.

Isaac, R. and Walker, J.M. (1985). Information and Conspiracy in Sealed-Bid Auctions. Journal of Economic Behavior and Organization, 6, 139-159.

Kalra, A., \& Shi, M. (2010). Consumer Value Maximizing Sweepstakes and Contests. Journal of Marketing Research, 47, 287-300.

Konrad, K.A. (2009). Strategy and Dynamics in Contests. New York, NY: Oxford University Press.

Kuhnen, C.M., \& Tymula, A. (2012). Feedback, self-esteem and performance in organizations. Management Science, forthcoming.

Leininger, W. (2003). On evolutionarily stable behavior in contests. Economics of Governance, 4, 177-186.

Ludwig, S., \& Lunser, G.K. (2009). Knowing the Gap - Intermediate Information in Tournaments. Working Paper.

Lugovskyy, V., Puzzello, D., \& Tucker, S. (2010). An Experimental Investigation of Overdissipation in the All Pay Auction. European Economic Review, 54, 974-997.

Mago, S.D., Sheremeta, R.M., \& Yates, A. (2011). Best of Three Contests: Experimental Evidence. ESI Working Paper.

Millner, E.L., \& Pratt, M.D. (1989). An Experimental Investigation of Efficient Rent-Seeking. Public Choice, 62, 139-151.

Moldovanu, B., Sela, A., \& Shi, X. (2007). Contest for Status. Journal of Political Economy, 115, 338-363.

Potter, T. (1999). Buckley v. Valeo, Political Disclosure and the First Amendment. Akron Law Review, 33, 71-103.

Potters, J.C., De Vries, C.G., \& Van Winden, F. (1998). An Experimental Examination of Rational Rent Seeking. European Journal of Political Economy, 14, 783-800.

Price, C.R., \& Sheremeta, R.M. (2011). Endowment Effects in Contests. Economics Letters, 111, 217-219.

Rege, M., \& Telle K., (2004). The impact of social approval and framing on cooperation in public good situations. Journal of Public Economics, 88, 1625-1644.

Riechmann, T. (2007). An analysis of rent-seeking games with relative-payoff maximizers. Public Choice, 133, 147-155. 
Rietz, T., Sheremeta, R.M., Shields, T.W., \& Smith, V.L. (2012). Transparency, Efficiency and the Distribution of Economic Welfare in Pass-Through Investment Trust Games. ESI Working Paper.

Savikhin, A., \& Sheremeta, R.M. (2011). Visibility of Contributors and Cost of Information: An Experiment on Public Goods. ESI Working Paper.

Scharlemann, J P W, Eckel, C C, Kacelnik, A \& Wilson, R K (2001). The value of a smile: game theory with a human face. Journal of Economic Psychology, 22, 617-640.

Sheremeta, R.M. \& Zhang. J. (2010). Can Groups Solve the Problem of Over-Bidding in Contests? Social Choice and Welfare, 35, 175-197.

Sheremeta, R.M. (2010). Expenditures and Information Disclosure in Two-Stage Political Contests. Journal of Conflict Resolution, 54, 771-798

Sheremeta, R.M. (2010). Experimental Comparison of Multi-Stage and One-Stage Contests. Games and Economic Behavior, 68, 731-747.

Sheremeta, R.M. (2011). Contest Design: An Experimental Investigation. Economic Inquiry, 49, 573-590.

Sheremeta, R.M., Dechenaux, E., \& Kovenock, D. (2012). A Survey of Experimental Research on Contests, All-Pay Auctions and Tournaments. ESI Working Paper.

Smither, J.W., London, M., \& Reilly, R.R. (2005). Does performance improve following multisource feedback? A theoretical model, meta-analysis, and review of empirical findings. Personnel Psychology, 58, 33-66.

Tajfel, H. \& Turner, J. (1979). An Integrative Theory of Intergroup Conflict. In Stephen Worchel and William Austin, eds., The Social Psychology of Intergroup Relations, Monterey, CA: Brooks/Cole.

Thomas, C. J. \& Wilson, B. J. (2002). A comparison of auctions and multilateral negotiations. The RAND Journal of Economics, 33, 140-155.

Tullock, G. (1980). Efficient Rent Seeking. In J.M. Buchanan, R.D. Tollison, G. Tullock, (Eds.), Toward a theory of the rent-seeking society. College Station, TX: Texas A\&M University Press, pp. 97-112.

Vriend, N. J. (2000). An illustration if the essential difference between individual and social learning, and its consequences for computational analyses. Journal of Economic Dynamics and Control, 24, 1-19.

Whitaker, L. P. (2008). The Constitutionality of Campaign Finance Regulation: Buckley v. Valeo and Its Supreme Court Progeny. CRS Report for the Congress, RL30669. 


\section{Tables and Figures}

Table 1: Summary of Treatments

\begin{tabular}{|c|c|c|}
\hline $\begin{array}{l}\text { Varying Information } \Rightarrow \\
\text { Varying Identification } \Downarrow\end{array}$ & $\begin{array}{l}\begin{array}{l}\text { No Information } \\
\text { (only own effort) }\end{array} \\
\end{array}$ & $\begin{array}{c}\text { Information } \\
\text { (all group members' efforts) }\end{array}$ \\
\hline $\begin{array}{c}\text { No Photo } \\
\text { (identities not revealed) }\end{array}$ & $\begin{array}{c}\text { No Photo, No Information } \\
\text { (NP-NI) } \\
2 \text { sessions (60 subjects) }\end{array}$ & $\begin{array}{c}\text { No Photo, Information } \\
\text { (NP-I) } \\
2 \text { sessions (60 subjects) }\end{array}$ \\
\hline $\begin{array}{c}\text { Photo } \\
\text { (identities revealed) }\end{array}$ & $\begin{array}{c}\text { Photo, No Information } \\
\text { (P-NI) } \\
2 \text { sessions (60 subjects) }\end{array}$ & $\begin{array}{c}\text { Photo, Information } \\
\text { (P-I) } \\
2 \text { sessions (60 subjects) }\end{array}$ \\
\hline
\end{tabular}

Table 2: Average Effort, Payoff and Dissipation Rate

\begin{tabular}{lccccc}
\hline \hline \multicolumn{1}{c}{ Treatment } & Nash & NP-NI & NP-I & P-NI & P-I \\
\hline Effort, $e$ & 15 & $29.1(0.7)$ & $28.3(0.7)$ & $25.1(0.6)$ & $24.1(0.6)$ \\
Payoff, $E(\pi)$ & 7.5 & $-9.1(0.9)$ & $-8.3(1.0)$ & $-5.1(1.0)$ & $-4.1(1.0)$ \\
Dissipation Rate, $d$ & 0.75 & $1.46(0.02)$ & $1.41(0.02)$ & $1.26(0.02)$ & $1.20(0.02)$ \\
Non-monetary Effort, $e_{o}$ & 0 & $10.8(0.5)$ & $7.7(0.4)$ & $6.9(0.5)$ & $7.0(0.4)$ \\
\hline
\end{tabular}

Standard error of the mean in parentheses.

Table 3: Volatility of Effort Within Group and Between Periods

\begin{tabular}{lcccc}
\hline Treatment & NP-NI & NP-I & P-NI & P-I \\
\hline & \multicolumn{4}{c}{ Within Group Volatility } \\
\hline Periods 1-5 & $16.5(0.65)$ & $14.1(0.62)$ & $14.1(0.62)$ & $11.5(0.53)$ \\
Periods 16-20 & $18.1(0.71)$ & $16.0(0.69)$ & $14.7(0.66)$ & $12.9(0.62)$ \\
Periods 1-20 & $18.1(0.35)$ & $14.7(0.33)$ & $13.87(0.31)$ & $12.0(0.29)$ \\
\hline & \multicolumn{4}{c}{ Between Periods Volatility } \\
\hline Periods 1-5 & $15.6(1.21)$ & $15.7(1.03)$ & $14.1(1.11)$ & $13.2(1.03)$ \\
Periods 16-20 & $9.17(0.97)$ & $16.9(1.28)$ & $13.8(1.19)$ & $13.3(1.15)$ \\
Periods 1-20 & $14.2(0.59)$ & $16.0(0.56)$ & $13.9(0.53)$ & $13.6(0.50)$ \\
\hline String
\end{tabular}

Standard error of the mean in parentheses. When calculating the between periods volatility one period is omitted because of the lag variable. 
Table 4: Panel Estimation of Determinants of Effort (Lags)

\begin{tabular}{|c|c|c|}
\hline Dependent variable, effort & NP-NI and P-NI & NP-I and P-I \\
\hline Specification & (1) & (2) \\
\hline $\begin{array}{l}\text { Photo } \\
\quad[1 \text { if photo treatment }]\end{array}$ & $\begin{array}{l}-1.68 \\
(1.31)\end{array}$ & $\begin{array}{l}-2.27 \\
(1.67)\end{array}$ \\
\hline $\begin{array}{l}\text { effort-lag } \\
\quad[\text { own effort in } t \text {-1] }\end{array}$ & $\begin{array}{c}0.49 * * * \\
(0.05)\end{array}$ & $\begin{array}{c}0.50^{* * * *} \\
(0.04)\end{array}$ \\
\hline $\begin{array}{l}\text { win-lag } \\
\quad[\text { own win in } t \text {-1] }\end{array}$ & $\begin{array}{l}1.79 \\
(2.52)\end{array}$ & $\begin{array}{l}-1.61 \\
(1.88)\end{array}$ \\
\hline $\begin{array}{l}\text { above-lag } \\
\quad[1 \text { if above the winning effort in } t-1]\end{array}$ & $\begin{array}{l}-1.51 \\
(2.65)\end{array}$ & $\begin{array}{c}-4.35 * * * \\
(1.65)\end{array}$ \\
\hline $\begin{array}{l}\text { below-lag } \\
\quad[1 \text { if below the winning effort in } t-1]\end{array}$ & $\begin{array}{l}2.67 \\
(2.58)\end{array}$ & $\begin{array}{c}5.34 * * * \\
(1.88)\end{array}$ \\
\hline $\begin{array}{l}\text { Period } \\
\quad \text { [period trend] }\end{array}$ & $\begin{array}{c}-0.25 * * * \\
(0.07)\end{array}$ & $\begin{array}{l}-0.19^{* *} \\
(0.07)\end{array}$ \\
\hline Constant & $\begin{array}{l}15.43 * * * \\
(3.04)\end{array}$ & $\begin{array}{c}14.95 * * * \\
(3.30)\end{array}$ \\
\hline Observations & 2,280 & 2,280 \\
\hline
\end{tabular}

* significant at $10 \%$, ** significant at $5 \%$, *** significant at $1 \%$.

The standard errors in parentheses are clustered at the group level. All models include a random effects error structure, with the individual subject as the random effect, to account for the multiple decisions made by individual subjects.

Table 5: Panel Estimation of Determinants of Effort (Non-Monetary Utility)

\begin{tabular}{lccccc}
\hline \hline Dependent variable, effort & All & NP-NI & NP-I & P-NI & P-I \\
\hline Specification & $(1)$ & $(2)$ & $(3)$ & $(4)$ & $(5)$ \\
\hline information & -0.37 & & & & \\
$\quad[1$ if full information 0 otherwise] & $(1.91)$ & & & & \\
identification & $-3.76^{* *}$ & & & & \\
$\quad[1$ if photo and 0 otherwise] & $(1.92)$ & & & & \\
non-monetary & $0.21^{* * *}$ & $0.26^{* * *}$ & $0.28^{*}$ & $0.20^{* * *}$ & 0.08 \\
$\quad[$ effort for prize 0] & $(0.05)$ & $(0.07)$ & $(0.14)$ & $(0.05)$ & $(0.13)$ \\
period & $-0.33^{* * *}$ & $-0.50^{* * *}$ & -0.27 & $-0.25^{* *}$ & $-0.29^{* *}$ \\
$\quad$ [period trend] & $(0.07)$ & $(0.10)$ & $(0.20)$ & $(0.11)$ & $(0.14)$ \\
quiz & -1.56 & -0.19 & -3.95 & -0.69 & $-2.26^{*}$ \\
$\quad$ [\# correct answers on the quiz] & $(1.11)$ & $(2.89)$ & $(2.86)$ & $(1.72)$ & $(1.20)$ \\
constant & $37.25^{* * *}$ & $32.42^{* *}$ & $46.52^{* * *}$ & $29.21 * * *$ & $36.44^{* * *}$ \\
& $(5.55)$ & $(13.18)$ & $(14.76)$ & $(7.74)$ & $(5.85)$ \\
\hline Observations & 4,800 & 1,200 & 1,200 & 1,200 & 1,200 \\
\hline
\end{tabular}

$*$ significant at $10 \%, * *$ significant at $5 \%$, *** significant at $1 \%$.

The standard errors in parentheses are clustered at the group level. All models include a random effects error structure, with the individual subject as the random effect, to account for the multiple decisions made by individual subjects. 
Figure 1: Average Effort by Treatments

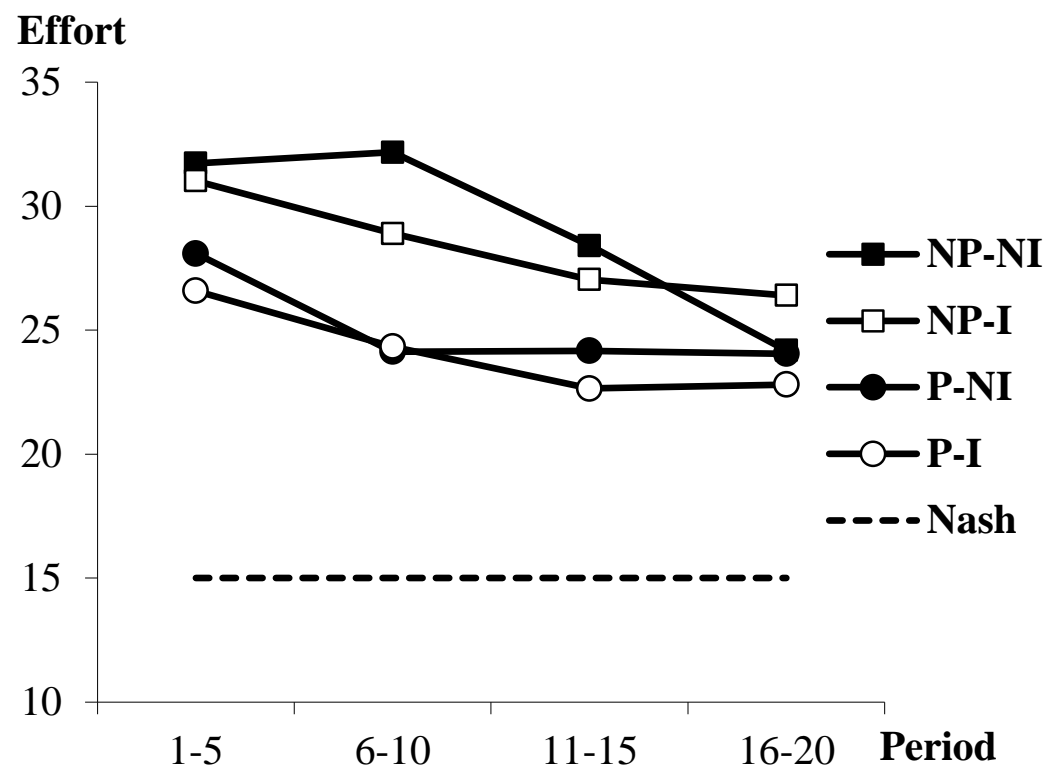


Figure 2: Distribution of Efforts
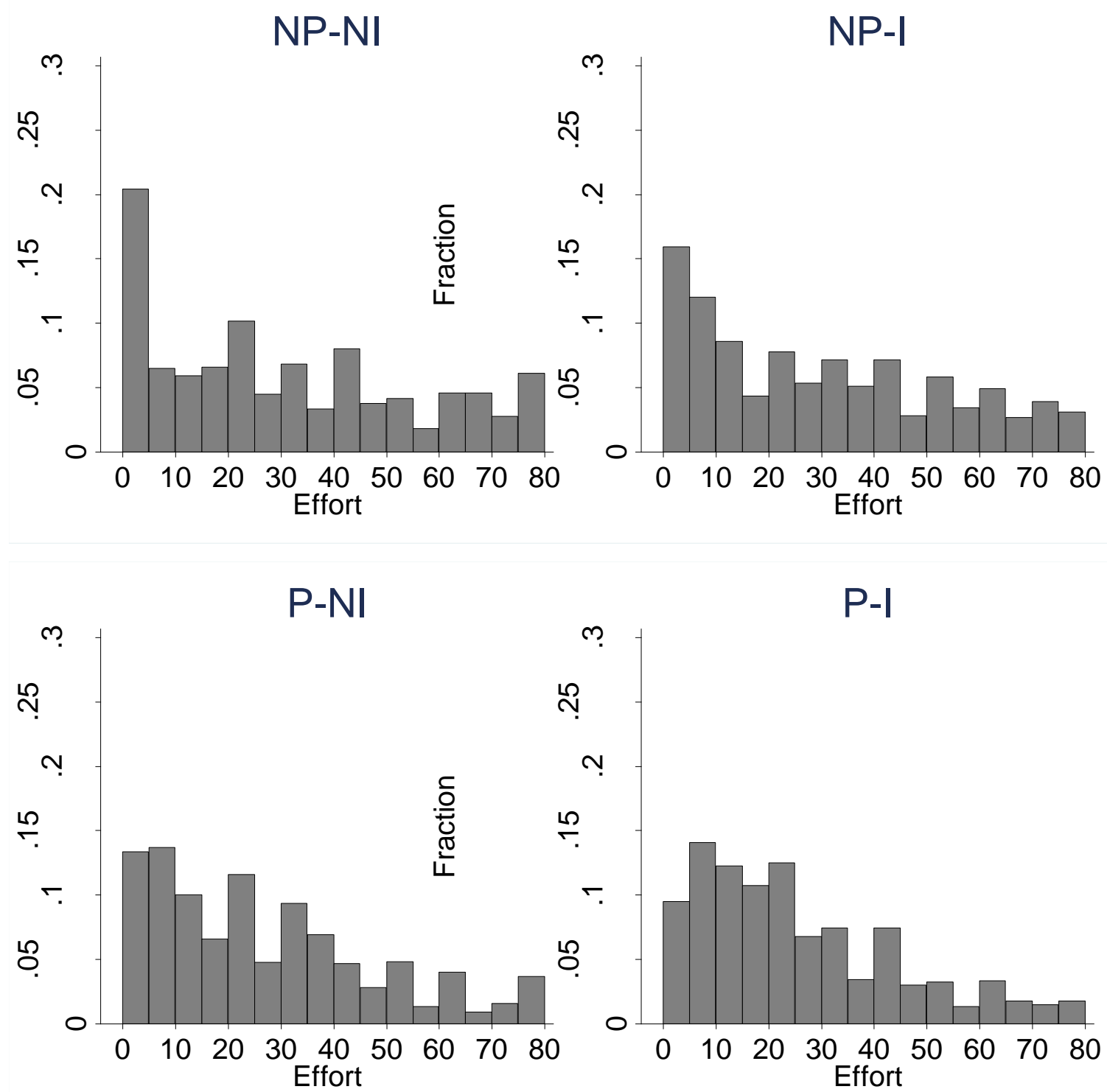


\section{Appendix: Instructions for P-I Treatment}

In this experiment you will be placed in a group of $\mathbf{4}$ participants (including you). You will remain in the same group for the entire experiment. The experiment will consist of 20 periods. At the end of the experiment 2 out of 20 periods will be randomly selected for payment. After you have completed all periods two tokens will be randomly drawn out of a bingo cage containing tokens numbered from 1 to 20 . The token numbers determine which two periods are going to be paid in the game.

Each period you will be given 80 francs. Francs will be converted to U.S. dollars at the end of the experiment at the rate of $\mathbf{1 5}$ francs $=\$ \mathbf{1}$. Each period, you will select a bid.

Each group member will receive a randomly chosen ID for the experiment (a number from 1 to 4). Your ID will remain the same for the entire experiment. The photos and names of each member of your group will be displayed on the top of your screen at all times below each member's ID.

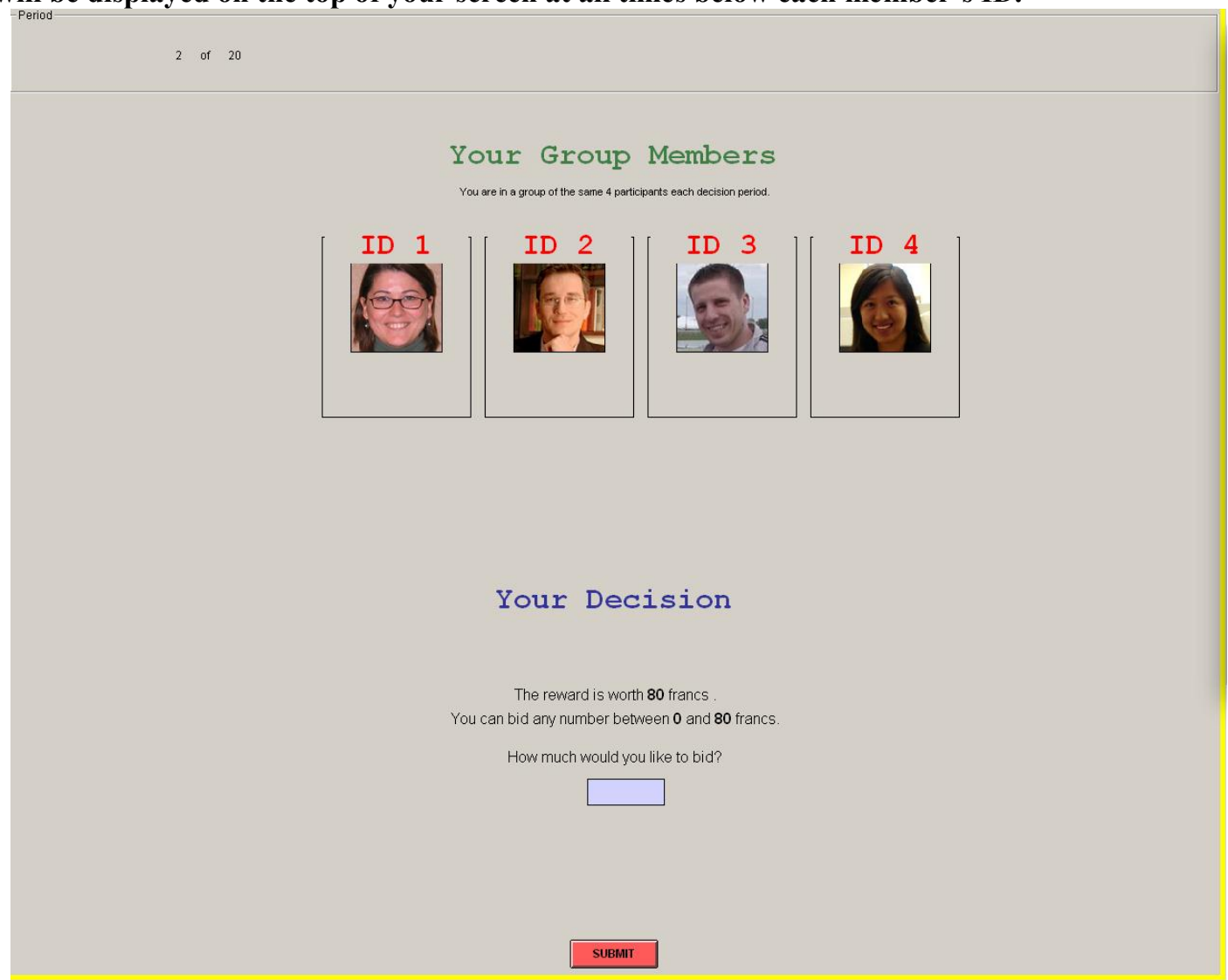

Each period, you and all other participants will be given an initial endowment of $\mathbf{8 0}$ francs and you will be asked to decide how much you want to bid for a reward. The reward is worth $\mathbf{8 0}$ francs to you and the other four participants in your group. You may bid any integer number of francs between $\mathbf{0}$ and $\mathbf{8 0}$. After all participants have made their decisions, your earnings for the period are calculated. These earnings will be converted to cash and paid at the end of the experiment if the current period is the period that is randomly chosen for payment. If you receive the reward your period earnings are equal to your endowment plus the reward minus your bid. If you do not receive the reward your period earnings are equal to your endowment minus your bid.

If you receive the reward: $\quad$ Earnings $=$ Endowment + Reward - Your Bid $=80+80-$ Your Bid If you do not receive the reward: Earnings $=$ Endowment - Your Bid $=80-$ Your Bid

The more you bid, the more likely you are to receive the reward. The more the other participants in your group bid, the less likely you are to receive the reward. Specifically, for each franc you bid you will receive one lottery ticket. At the end of each period the computer draws randomly one ticket among all the tickets purchased by 4 participants in the group, including you. The owner of the drawn ticket receives the reward of 80 francs. Thus, your chance of receiving the reward is given by the number of francs you bid divided by the total number of francs 
all 4 participants in your group bid. You can never guarantee yourself the reward. However, by increasing your bid, you can increase your chance of receiving the reward. Regardless of who receives the reward, all participants will have to pay their bids.

Chance of receiving the $\quad=\frac{\text { Your Bid }}{\text { reward }}$
In case all participants bid zero, the reward is randomly assigned to one of the 4 participants in the group.

Example: Let's say participant 1 bids 10 francs, participant 2 bids 15 francs, participant 3 bids 0 francs, and participant 4 bids 40 francs. Therefore, the computer assigns 10 lottery tickets to participant 1,15 lottery tickets to participant 2, 0 lottery tickets to participant 3 , and 40 lottery tickets for participant 4 . Then the computer randomly draws one lottery ticket out of $65(10+15+0+40)$. As you can see, participant 4 has the highest chance of receiving the reward: $0.62=\mathbf{4 0 / 6 5}$. Participant 2 has $0.23=\mathbf{1 5 / 6 5}$ chance, participant 1 has $0.15=\mathbf{1 0 / 6 5}$ chance, and participant 3 has $\mathbf{0}=\mathbf{0 / 6 5}$ chance of receiving the reward.

After all participants make their bids, the computer will make a random draw which will decide who receives the reward. Then the computer will calculate your period earnings based on your bid and whether you received the reward or not.

\section{OUTCOME SCREEN}

At the end of each period, your bid, whether you received the reward or not, and your earnings for the period are reported on the outcome screen as shown below. Once the outcome screen is displayed you should record your results for the period on your Personal Record Sheet under the appropriate heading.

In addition, you will see the bids of your group members by their ID numbers and whether they received the reward. The photos and names of all your group members will also be displayed on the outcome screen above their IDs.

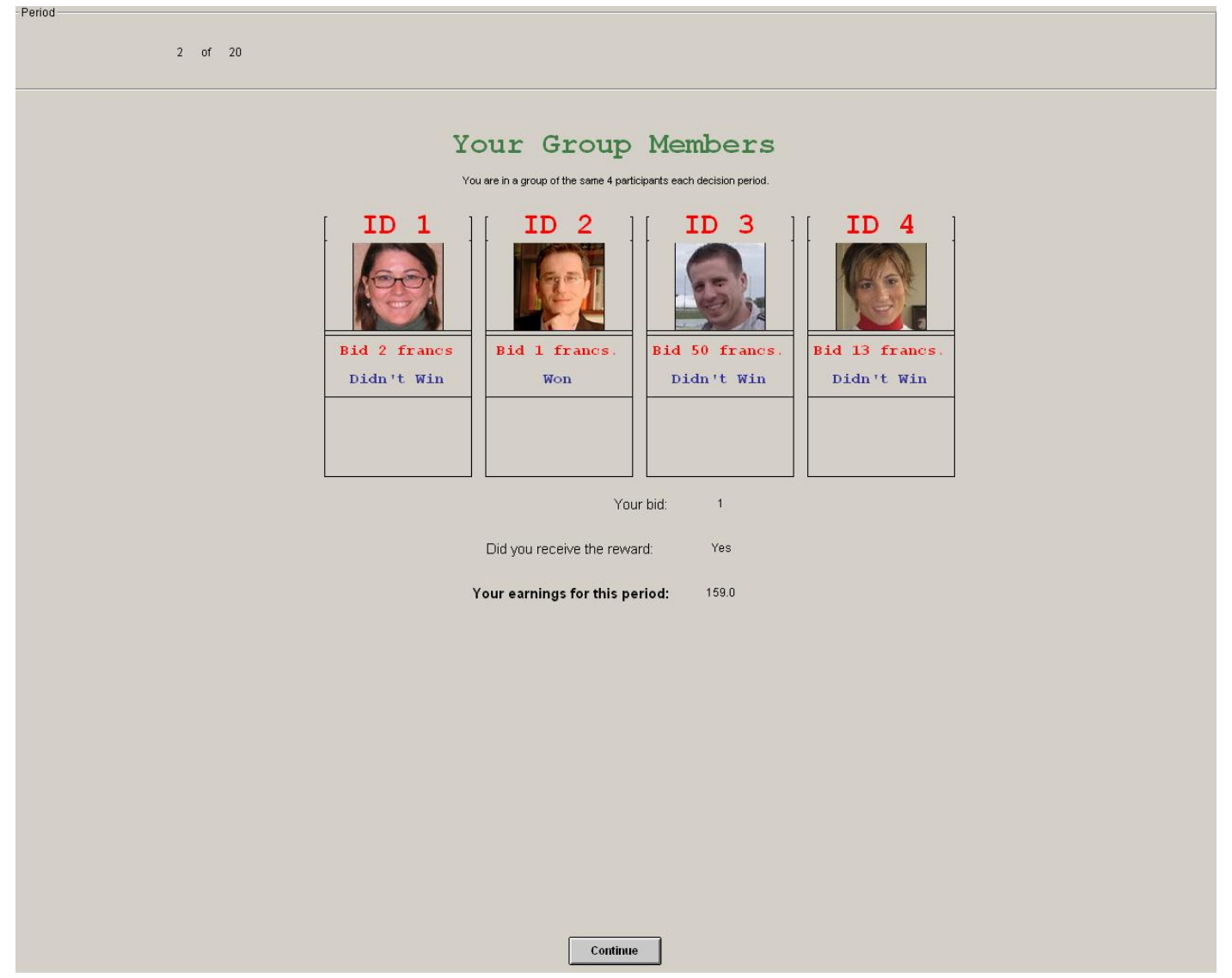




\section{2}

\section{Economic Science Institute Working Papers}

12-14 McCarter, M., Kopelman, S., Turk, T. and Ybarra, C. Too Many Cooks Spoil the Broth: How the tragedy of the anticommons emerges in organizations.

12-13 Chowdhury, S., Sheremeta, R. and Turocy, T. Overdissipation and Convergence in Rent-seeking Experiments: Cost structure and prize allocation rules.

12-12 Bodsky, R., Donato, D., James, K. and Porter, D. Experimental Evidence on the Properties of the California’s Cap and Trade Price Containment Reserve.

12-11 Branas-Garza, P., Espin, A. and Exadaktylos, F. Students, Volunteers and Subjects: Experiments on Social Preferences.

12-10 Klose, B. and Kovenock, D. Extremism Drives Out Moderation.

12-09 Buchanan, J. and Wilson, B. An Experiment on Protecting Intellectual Property.

12-08 Buchanan, J., Gjerstad, S. and Porter, D. Information Effects in Multi-Unit Dutch Auctions.

12-07 Price, C. and Sheremeta, R. Endowment Origin, Demographic Effects and Individual Preferences in Contests.

12-06 Magoa, S. and Sheremeta, R. Multi-Battle Contests: An experimental study.

12-05 Sheremeta, R. and Shields, T. Do Liars Believe? Beliefs and Other-Regarding Preferences in Sender-Receiver Games.

12-04 Sheremeta, R., Masters, W. and Cason. T. Winner-Take-All and Proportional-Prize Contests: Theory and experimental results.

12-03 Buchanan, J., Gjerstad, S. and Smith, V. There’s No Place Like Home.

12-02 Corgnet, B. and Rodriguez-Lara, I. Are you a Good Employee or Simply a Good Guy? Influence Costs and Contract Design.

12-01 Kimbrough, E. and Sheremeta, R. Side-Payments and the Costs of Conflict.

2011

11-20 Cason, T., Savikhin, A. and Sheremeta, R. Behavioral Spillovers in Coordination Games.

11-19 Munro, D. and Rassenti, S. Combinatorial Clock Auctions: Price direction and performance.

11-18 Schniter, E., Sheremeta, R., and Sznycer, D. Restoring Damaged Trust with Promises, Atonement and Apology. 
11-17 Brañas-Garza, P., and Proestakis, A. Self-discrimination: A field experiment on obesity.

11-16 Brañas-Garza, P., Bucheli, M., Paz Espinosa, M., and García-Muñoz, T. Moral Cleansing and Moral Licenses: Experimental evidence.

11-15 Caginalp, G., Porter, D., and Hao, L. Asset Market Reactions to News: An experimental study.

11-14 Benito, J., Branas-Garz, P., Penelope Hernandez, P., and Sanchis Llopis, J. $\underline{\text { Strategic Behavior in }}$ Schelling Dynamics: A new result and experimental evidence.

11-13 Chui, M., Porter, D., Rassenti, S. and Smith, V. The Effect of Bidding Information in Ascending Auctions.

11-12 Schniter, E., Sheremeta, R. and Shields, T. Conflicted Minds: Recalibrational emotions following trust-based interaction.

11-11 Pedro Rey-Biel, P., Sheremeta, R. and Uler, N. (Bad) Luck or (Lack of) Effort?: Comparing social sharing norms between US and Europe.

11-10 Deck, C., Porter, D., and Smith, V. Double Bubbles in Assets Markets with Multiple Generations.

11-09 Kimbrough, E., Sheremeta, R., and Shields, T. Resolving Conflicts by a Random Device.

11-08 Brañas-Garza, P., García-Muñoz, T., and Hernan, R. Cognitive effort in the Beauty Contest Game.

11-07 Grether, D., Porter, D., and Shum, M. Intimidation or Impatience? Jump Bidding in On-line Ascending Automobile Auctions.

11-06 Rietz, T., Schniter, E., Sheremeta, R., and Shields, T. Trust, Reciprocity and Rules.

11-05 Corgnet, B., Hernan-Gonzalez, R., and Rassenti, S. Real Effort, Real Leisure and Real-time Supervision: Incentives and peer pressure in virtual organizations.

11-04 Corgnet, B. and Hernán-González R. Don’t Ask Me If You Will Not Listen: The dilemma of participative decision making.

11-03 Rietz, T., Sheremeta, R., Shields, T., and Smith, V. Transparency, Efficiency and the Distribution of Economic Welfare in Pass-Through Investment Trust Games.

11-02 Corgnet, B., Kujal, P. and Porter, D. The Effect of Reliability, Content and Timing of Public Announcements on Asset Trading Behavior.

11-01 Corgnet, B., Kujal, P. and Porter, D. Reaction to Public Information in Markets: How much does ambiguity matter?

2010

10-23 Sheremeta, R. Perfect-Substitutes, Best-Shot, and Weakest-Link Contests between Groups. 
10-22 Mago, S., Sheremeta, R., and Yates, A. Best-of-Three Contests: Experimental Evidence.

10-21 Kimbrough, E. and Sheremeta, R. Make Him an Offer He Can't Refuse: Avoiding conflicts through side payments.

10-20 Savikhim, A. and Sheremeta, R. Visibility of Contributions and Cost of Inflation: An experiment on public goods.

10-19 Sheremeta, R. and Shields, T. Do Investors Trust or Simply Gamble?

10-18 Deck, C. and Sheremeta, R. Fight or Flight? Defending Against Sequential Attacks in the Game of Siege.

10-17 Deck, C., Lin, S. and Porter, D. Affecting Policy by Manipulating Prediction Markets: Experimental evidence.

10-16 Deck, C. and Kimbrough, E. Can Markets Save Lives? An Experimental Investigation of a Market for Organ Donations.

10-15 Deck, C., Lee, J. and Reyes, J. Personality and the Consistency of Risk Taking Behavior: Experimental Evidence.

10-14 Deck, C. and Nikiforakis, N. Perfect and Imperfect Real-Time Monitoring in a Minimum-Effort Game.

10-13 Deck, C. and Gu, J. Price Increasing Competition? Experimental Evidence.

10-12 Kovenock, D., Roberson, B., and Sheremeta, R. The Attack and Defense of Weakest-Link Networks.

10-11 Wilson, B., Jaworski, T., Schurter, K. and Smyth, A. An Experimental Economic History of Whalers' Rules of Capture.

10-10 DeScioli, P. and Wilson, B. Mine and Thine: The territorial foundations of human property.

10-09 Cason, T., Masters, W. and Sheremeta, R. Entry into Winner-Take-All and Proportional-Prize

Contests: An experimental study.

10-08 Savikhin, A. and Sheremeta, R. Simultaneous Decision-Making in Competitive and Cooperative Environments.

10-07 Chowdhury, S. and Sheremeta, R. A generalized Tullock contest.

10-06 Chowdhury, S. and Sheremeta, R. The Equivalence of Contests.

10-05 Shields, T. Do Analysts Tell the Truth? Do Shareholders Listen? An Experimental Study of Analysts' Forecasts and Shareholder Reaction. 
10-04 Lin, S. and Rassenti, S. Are Under- and Over-reaction the Same Matter? A Price Inertia based Account.

10-03 Lin, S. Gradual Information Diffusion and Asset Price Momentum.

10-02 Gjerstad, S. and Smith, V. Household Expenditure Cycles and Economic Cycles, 1920 - 2010.

10-01 Dickhaut, J., Lin, S., Porter, D. and Smith, V. Durability, Re-trading and Market Performance.

\section{9}

09-11 Hazlett, T., Porter, D., and Smith, V. Radio Spectrum and the Disruptive Clarity OF Ronald Coase.

09-10 Sheremeta, R. Expenditures and Information Disclosure in Two-Stage Political Contests.

09-09 Sheremeta, R. and Zhang, J. Can Groups Solve the Problem of Over-Bidding in Contests?

09-08 Sheremeta, R. and Zhang, J. Multi-Level Trust Game with "Insider" Communication.

09-07 Price, C. and Sheremeta, R. Endowment Effects in Contests.

09-06 Cason, T., Savikhin, A. and Sheremeta, R. Cooperation Spillovers in Coordination Games.

09-05 Sheremeta, R. Contest Design: An experimental investigation.

09-04 Sheremeta, R. Experimental Comparison of Multi-Stage and One-Stage Contests.

09-03 Smith, A., Skarbek, D., and Wilson, B. Anarchy, Groups, and Conflict: An experiment on the emergence of protective associations.

09-02 Jaworski, T. and Wilson, B. Go West Young Man: Self-selection and endogenous property rights.

09-01 Gjerstad, S. Housing Market Price Tier Movements in an Expansion and Collapse.

\section{8}

08-09 Dickhaut, J., Houser, D., Aimone, J., Tila, D. and Johnson, C. $\underline{\text { High Stakes Behavior with Low }}$ Payoffs: Inducing preferences with Holt-Laury gambles.

08-08 Stecher, J., Shields, T. and Dickhaut, J. Generating Ambiguity in the Laboratory.

08-07 Stecher, J., Lunawat, R., Pronin, K. and Dickhaut, J. Decision Making and Trade without Probabilities.

08-06 Dickhaut, J., Lungu, O., Smith, V., Xin, B. and Rustichini, A. A Neuronal Mechanism of Choice. 
08-05 Anctil, R., Dickhaut, J., Johnson, K., and Kanodia, C. Does Information Transparency Decrease Coordination Failure?

08-04 Tila, D. and Porter, D. Group Prediction in Information Markets With and Without Trading Information and Price Manipulation Incentives.

08-03 Thomas, C. and Wilson, B. Horizontal Product Differentiation in Auctions and Multilateral Negotiations.

08-02 Oprea, R., Wilson, B. and Zillante, A. War of Attrition: Evidence from a laboratory experiment on market exit.

08-01 Oprea, R..2 Porter, D., Hibbert, C., Hanson, R. and Tila, D. Can Manipulators Mislead Prediction Market Observers? 